Review

\title{
Fertility Sparing Management in Non-Epithelial Ovarian Cancer. Which Patients, What Procedure and What Outcome?
}

\author{
Nikolaos Thomakos ${ }^{1}$, Anastasios Malakasis ${ }^{1}$, Nikolaos Machairiotis ${ }^{1}$, Paul Zarogoulidis ${ }^{2}$, Alexandros \\ Rodolakis ${ }^{1}$ \\ 1. First Department of Obstetrics and Gynecology, Alexandra Hospital, Gynecologic Oncology Unit, University of Athens, Athens, Greece \\ 2. 3rd Department of Surgery, "AHEPA" University Hospital, Aristotle University of Thessaloniki, Medical School, Thessaloniki, Greece \\ $\square$ Corresponding author: Paul ZarogoulidisM.D, Ph.D., 3rd Department of Surgery, "AHEPA" University Hospital, Aristotle University of Thessaloniki, \\ Medical School, Thessaloniki, Greece. Mobile: 00306977271974; E-mail: pzarog@hotmail.com \\ (c) Ivyspring International Publisher. This is an open access article distributed under the terms of the Creative Commons Attribution (CC BY-NC) license \\ (https://creativecommons.org/licenses/by-nc/4.0/). See http://ivyspring.com/terms for full terms and conditions.
}

Received: 2018.04.14; Accepted: 2018.09.15; Published: 2018.11.24

\begin{abstract}
Non epithelial ovarian tumors represent a small group of rare gynecological cancers but they have a high incidence in young childbearing women. The recent years fertility preservation surgeries have become a common practice in specific ovarian malignancies when the patients wish to maintain their fertility. Specific types of non-epithelial ovarian tumors can be managed with fertility sparing operations with a similar outcome to more radical intervention but due to the rarity of these tumors the extent of the operation remains in some cases controversial. Moreover, the reproductive outcome of the women that had these conservative operations seems to be very promising. In our review we try to summarize the data regarding the fertility sparing management of all types of non-epithelial ovarian cancers and what procedure should be performed in each case. Finally we have accumulated the data concerning the reproductive outcome of patients that had undergone this type of surgery.
\end{abstract}

Key words: non-epithelial ovarian cancer, fertility preservation, reproductive outcome

\section{Introduction}

Ovarian cancer represents approximately $27 \%$ of all the gynecologic cancers.[1] In most cases they are of epithelial origin ( $85-90 \%$ ); whereas the remaining cases constitute a significant group of non-epithelial malignant ovarian tumors. Non epithelial ovarian tumors which represent $10 \%$ of ovarian malignancies [2] can be differentiated in 2 major groups : Germ Cell Tumors (GCT) (5\%) [3] and Sex Cord Stromal Tumors (SCST) (3\%). GCTs originate from the primitive germ cells that migrate to the gonad at the 6th week of intrauterine life of the embryo.[4] The main categories of GCTs are dysgerminomas, endometrial sinus tumors, teratomas, embryonal carcinomas and mixed subtypes. The incidence of GCTs is higher in women of younger age and almost $70 \%$ are diagnosed in women under 30 years old. The peak incidence of this group is spotted in the age group of 15-19 years old[5]; hence fertility preservation represents a major issue during the course of their treatment. Sex cord stromal tumors arise from cells that can be found in the matrix of the ovary and consist of embryonic sex cord cells and mesenchymal cells. The main categories of SCST are pure stromal tumors (thecal cell tumors, steroid cell tumors, Leydig), pure sex cord tumors (granulosa cell tumors adult and juvenile, Sertoli cell tumors,sex cord tumor with annular tubules) and mixed sex cord-stromal tumors ( Sertoli-Leydig). Their incidence is widely distributed among the various age groups; however, their peak incidence is observed between 50 and 80 years old.[6] The objective of our review is to summarize the management of non-epithelial ovarian tumors and to focus specifically to their conservative management which aims to fertility preservation. Finally we have accumulated data concerning fertility potential and reproductive outcomes after conservative treatment. 


\section{Staging of non-epithelial ovarian tumors}

Non-epithelial ovarian tumors are staged similarly to epithelial ovarian tumors according to current guidelines proposed by the International Federation of Gynecology and Obstetrics (FIGO).[7] Laparotomy and laparoscopy, along with the robotic approach, can be used for this purpose. However, in contrast to early stage ovarian cancer, current evidence in this field are extremely limited.[8] A full staging operation of non-epithelial tumors should include peritoneal washings, infracolic omentectomy, biopsies of the diaphragmatic peritoneum, paracolic gutters and pelvic peritoneum.[9] Lymph node dissection is not mandatory except if there is obvious nodal disease.[10] The extent of the operation depends on the type of malignancy and intraoperative findings; however, nowadays, oncological procedures tend to be less invasive in order to preserve fertility in a large amount of patients that fulfill the criteria to undergo fertility sparing operations without compromising their life expectancy. Fertility sparing procedures are restricted to patients that wish to conceive and provided that they are fully informed about the risks and risks of their decision. They should be offered to patients who comply with a very close follow-up and those with adequate fertility potential (generally, patients under 40 years). In addition the treatment should be individualized according to the histology and staging of the tumor.[11] Fertility sparing treatment is very important in patients with non-epithelial ovarian cancer as it is frequently found in young ages.

\section{Clinical Manifestation}

\section{Germ Cell Tumors}

\section{Dysgerminoma}

It is the most common germ cell tumor and commonly presents in reproductive aged women. Usually, they are diagnosed at an early stage, $70 \%$ at stage IA and $10 \%$ at stage IB. Only $15 \%$ of the cases are found in stages II and III and 5\% in stage IV.[2] The treatment of stage IA dysgerminomas is conservative and is restricted to unilateral salpingo-oophorectomy. The role of complete staging operation is still unclear and of controversial benefit.[12] Current evidence support that there is no need for adjuvant therapy at these patients; hence, making these patients excellent candidates for fertility sparing procedures. It is important to mention that the contralateral ovary is rarely involved (10-20\%). This is why it should not be removed or biopsied when it is macroscopically normal. When there is involvement of both ovaries a salpingo-oophorectomy is performed in the adnexa with the largest tumor and a contralateral cystectomy can be considered.[11] As mentioned, early stage dysgerminomas should be treated with fertility preserving procedures only, and are accompanied with favorable outcomes and long-term survival rates that can reach $100 \%$. Their recurrence rate is $15-25 \%$ and can be treated at the time of the relapse with a rate of cure which reaches 90\%.[13] Patients with stage IB -IC and even those with more advanced stages (II-III- IV) are also excellent candidates for fertility sparing procedure. These patients should undergo a debulking procedure with preservation of the uterus and at least one ovary. However, they must receive adjuvant platinum-based chemotherapy with the most used regimen to be bleomycinetoposide-cisplatin (BEP).[14] Radiotherapy, although curative in this type of malignancy, is rarely used as it leads to premature ovarian failure and restricts fertility potential.

\section{Yolk sac tumor (Endodermal Sinus Tumor)}

It is the second most common malignant ovarian germ cell tumor after dysgerminoma and it is a tumor of the younger ages with the median age of appearance to be the 18 years of life. It is a very aggressive malignancy with the tendency to metastasize rapidly to other intraperitoneal organs. In the past, the overall 5-year survival rate was up to $15 \%$.[15]The management of this type and the outcome of therapy has changed in the recent years with the use of several chemotherapy regimens which have significantly improved the survival rate.[16] Nowadays fertility preservation operation is widely accepted in patients with yolk sac tumors and has the same efficacy as radical surgery.[17] The fertility sparing operation should include a unilateral salpingo-oophorectomy and removal of all the visible tumor and should be followed by adjuvant chemotherapy and specifically the BEP regimen.[9] In a recent study, At 2015 Satoh investigated 211 patients in a large multicenter study and observed that BEP resulted in significant improvement in the 5-year OS (93.6\% vs $74.6 \% p<.001)$.[18] This is a fact applied to all stages of the disease, early and advanced and with the use of BEP the 5-year survival rate can reach up to 90\%.[19]

\section{Immature teratoma}

It is a very rare malignancy representing only $1 \%$ of all teratomas with a peak incidence at the first 20 years of life.[2] The management of the immature teratomas depends on the histopathological type and grade. The latter index is directly related to the patients' overall survival rate when immature teratoma has been diagnosed.[20] All patients with 
this type of tumor are eligible for fertility sparing operations. Patients with stage IA and Grade 1 tumors are treated with unilateral salpingoophorectomy and complete staging (including peritoneal washing and omental biopsy). Adjuvant chemotherapy is not required in these patients.[21] Moreover, it should be mentioned that evidence concerning the need for adjuvant chemotherapy after fertility preservation surgery in patients with stage IA G2-G3 and stages IB and IC is still conflicting. Recently, however, Alwazzan et al presented a cohort study based on a thirty-year single tertiary center experience.[22] The authors specifically concluded that adjuvant treatment with BEP should be considered in stages greater than stage IA grade I. Other cohort studies also indicate that chemotherapy could be reserved for patients with disease recurrence [21], however, consensus still lacks in this field. All other stages (IIA IV) need adjuvant chemotherapy with BEP to be the gold standard treatment after the operation.

\section{Sex Cord Stromal Tumors}

\section{Granulosa cell tumor}

It is a rare neoplasm (2-5\% of all ovarian cancers) but it is the most common ovarian sex cord stromal tumor representing $70 \%$ of this category. It is distinguished in two different histological types, adult and juvenile. The peak incidence of the adult type is in the perimenopausal and early postmenopausal period.[23] On the other hand, the mean age of diagnosis of juvenile type is the age of 20.[24] This neoplasm is commonly managed with total hysterictomy and bilateral salpingo-oophorectomy followed by peritoneal washings, biopsies and infracolic omentectomy. Nodal dissection does not improve the survival rate and is not recommended in the absence of nodal disease.[25] Fertility sparing operation can be considered in stage IA, when the patient wishes to conceive.[11] The conservative operation includes a unilateral salpingo-oophorectomy and a staging operation. There is no need for biopsy of the contralateral ovary as the disease is unilateral in $98 \%$ of the cases.[26] It is important to mention that in patients with fertility sparing operations endometrial biopsy is mandatory to exclude the possibility of concurrent uterine cancer, as the risk is higher in these patients due to the potential estrogen-secreting ability of these tumors.[24] When advanced stage (>IA) is encountered the patient should be total abdominal hysterectomy and bilateral salpingo-oophorectomy and a full staging operation,, regardless of fertility issues. The patients who had a fertility sparing operation (stage IA) do not need adjuvant chemotherapy.[27] The need for follow-up operation in patients that have completed family planning remains debatable.[28]

\section{Sertoli-Leydig tumors}

This type of ovarian neoplasm is rare accounting for about $0.5 \%$ of all ovarian cancers and is mostly found in young women at the third decade of life.[29] These tumors are divided in well, moderate and poorly differentiated. There are also retiform variants. They occur more often in young women at the third decade of life.[30] The possibility of fertility sparing operation has to do not only with the stage but also with the histological type of the tumor.

Given these information, only young women with stage IA without retiform or poor differentiation or sarcomatoid histological type can be candidates for more conservative approach.[11] Conservative management includes unilateral salpingo-oophorectomy and staging procedure and there is no need for adjuvant chemotherapy. More advanced stages of the disease or the histological types mentioned above should be treated with a radical operation (total abdominal abdominal hysterectomy, bilateral salpingo-oophorectomy and full staging) followed by adjuvant chemotherapy.[9]

\section{Sex cord tumor with annular tubules}

This ovarian tumor is very rare as it represents only $6 \%$ of sex cord stromal tumors and current knowledge is limited in scarce evidence from small case series.It is found either alone or in association with Peutz-Jeghers syndrome.[31] When it is associated with Peutz-Jeghers syndrome it is almost always benign.[32] The sporadical type has a $20 \%$ malignancy rate and it is found almost always unilateral.[31] Because of the very limited literature and the unknown behavior of the tumor there is not a universal agreement about the treatment. Considering that the incidence of this tumor is mainly on the third and fourth decade of life, fertility sparing operation could be chosen.[33] The operation includes a unilateral salpingo-oopherectomy ad ipsilateral pelvic and para-aortic lymphadenectomy.[34] Conflicting evidence support, however, that lymphadenectomy may be omitted in sex-cord stroll tumors during staging operation without any adverse effects in survival rate.[25] Chemotherapy and radiotherapy is used in patients with metastases or recurrence.[35]

\section{Discussion}

\section{Lymphadenectomy}

Current evidence concerning the need for extensive surgery with the implementation of routine lymphadenectomy in patients with ovarian germ cell tumors remains confliting. At 2008 Kumar et al observed in a series of 613 patients that undergone 
pelvic lymphadenectomy that the incidence of lymph node metastases was $18.1 \%$.[36] The incidence was reported to be significantly higher in the case of dysgerminoma $(28 \%)$ and mixed germ cell tumors $(16 \%)$ compared to that of malignant teratoma $(8 \%)$. Several factors were deemed as potential predictors of lymph node involvement including age, race, grade of the lesion and extent of lymphadenectomy. On the other hand, Mahdi et al compared 493 patients with ovarian germ cell tumors confined to the ovary that undergone routine lymphadenectomy with 590 patients that did not have lymphadenectomy and observed that lymphadenectomy did not influence the 5-years survival rates.[10] The authors attributed their findings to the highly chemosensitive nature of these tumors and concluded that the addition of lymphadenectomy to current staging procedures did not benefit these patients. In a previous, smaller study that was based on outcomes from 102 women with ovarian germ cell tumors, Jin et al observed that lymphadenectomy was significantly related to the possibility of tumor relapse; however, after adjusting their analysis to the implemented chemotherapeutic regimen, this effect was lost, indicating that pelvic lymph node metastasis is not a significant factor related to patients prognosis. To date, all of the remaining evidence remains either anecdotal, or based on small case series; thus, prohibiting safe interpretation. Given the aforementioned data, one could assume that, although routine lymphadenectomy has not been introduced in international consensus as a routine procedure in germ cell tumors, it should be at least implemented in patients with dysgerminomas and mixed germ cell tumors.

Concerning sex cord stromal tumors two large cohorts have been published to support current evidence. Brown et al investigated 262 patients at 2009 and observed that of the 58 patients that were offered pelvic lymphadenectomy, none had positive nodes.[25] Recently, Nasioudis et al reviewed data from 1156 patients (572 underwent pelvic lymphadenectomy) and observed that only 3\% of them had metastases.[37] These authors also confirmed that the introduction of pelvic lymphadenectomy did not benefit the patients` survival. Thus, one could assume that the available evidence suggest against the implementation of pelvic lymphadenectomy as a routine procedure among patients with sex cord stromal tumors.

\section{Fertility and reproductive outcome}

Despite the strong recommendations for fertility preservation in patients with non-epithelial ovarian cancer; evidence concerning the reproductive function and fertility potential remain unclear. It is, therefore, important to conduct further studies in this field, to review the results after fertility sparing operations and the correlation of the conservative management with actual results in pregnancies and fertility maintenance. Despite the lack of adequate evidence in this field, scarce data support that the implementation of this strategy is encouraging.

Table 1. Summary of fertility sparing treatment in accordance to the type and stage of the tumor

\begin{tabular}{|c|c|c|c|}
\hline Type and stage of tumor & $\begin{array}{l}\text { Fertility sparing } \\
\text { option }\end{array}$ & $\begin{array}{l}\text { Fertility sparing } \\
\text { surgery }\end{array}$ & $\begin{array}{l}\text { Non-fertility sparing } \\
\text { surgery }\end{array}$ \\
\hline Dysgerminoma & & Unilateral salpingo-oophorectomy, peritoneal & If no fertility desired also bilateral \\
\hline Dysgerminoma stage IA-IV & Yes & $\begin{array}{l}\text { washing, omental biopsy and selective removal } \\
\text { of enlarged lymph nodes }\end{array}$ & $\begin{array}{l}\text { salpingo-ooporectomy and hysterectomy could } \\
\text { be considered }\end{array}$ \\
\hline Yolk-sac tumor & & Unilateral salpingo-oophorectomy, peritoneal & If no fertility desired also bilateral \\
\hline Yolk-sac tumor stage IA - IV & Yes & $\begin{array}{l}\text { washing, omental biopsy and selective removal } \\
\text { of enlarged lymph nodes }\end{array}$ & $\begin{array}{l}\text { salpingo-ooporectomy and hysterectomy could } \\
\text { be considered }\end{array}$ \\
\hline Immature teratoma & & Unilateral salpingo-oophorectomy, peritoneal & If no fertility desired also bilateral \\
\hline Immature teratoma stage IA - IV & Yes & $\begin{array}{l}\text { washing, omental biopsy and selective removal } \\
\text { of enlarged lymph nodes }\end{array}$ & $\begin{array}{l}\text { salpingo-ooporectomy and hysterectomy could } \\
\text { be considered }\end{array}$ \\
\hline \multicolumn{4}{|l|}{ Granulosa cell tumor } \\
\hline Granulosa cell tumor stage stage IA & Yes & $\begin{array}{l}\text { Unilateral salpingo-oophorectomy, peritoneal } \\
\text { washing, infra colic omentectomy and peritoneal } \\
\text { biopsies. Endometrial biopsies also required }\end{array}$ & \\
\hline Granulosa cell tumor stage stage IB-IV & No & & $\begin{array}{l}\text { Total abdominal hysterectomy and bilateral } \\
\text { salpingo-oophorectomy and full } \\
\text { staging/debulking surgery }\end{array}$ \\
\hline \multicolumn{4}{|l|}{ Sertoli-Leydig Tumors } \\
\hline $\begin{array}{l}\text { Sertoli-Leydig Tumor stage IA without } \\
\text { retiform or poor differentiation or } \\
\text { sarcomatoid histological type }\end{array}$ & Yes & $\begin{array}{l}\text { Unilateral salpingo-oophorectomy, peritoneal } \\
\text { washing, infra colic omentectomy and peritoneal } \\
\text { biopsies. Endometrial biopsies also required }\end{array}$ & \\
\hline $\begin{array}{l}\text { Sertoli-Leydig Tumor all other stages } \\
\text { and histological types }\end{array}$ & No & & $\begin{array}{l}\text { Total abdominal hysterectomy and bilateral } \\
\text { salpingo-oophorectomy and full } \\
\text { staging/debulking surgery }\end{array}$ \\
\hline Sex cord tumor with annular tubules & Yes & $\begin{array}{l}\text { Unilateral salpingo-oophorectomy, peritoneal } \\
\text { washing, infra colic omentectomy and peritoneal } \\
\text { biopsies. Endometrial biopsies also required }\end{array}$ & \\
\hline
\end{tabular}


As far as it concerns germ cell tumors we should highlight the following series. Zanetta et al reported a series of 169 patients with germ cell tumors. From this pool of patients 138 were treated conservatively and 128 maintained their menstruation. The final outcome was 55 pregnancies of 32 patients.[38] Tangir et al reported a series of 106 patients. From these 64 were treated conservatively and 32 maintained their menstruation. The final outcome was 38 pregnancies of 29 patients.[39] Finally, Low et al reported a series of 74 patients with germ cell tumor. All of them were treated conservatively, 43 maintained their menstruation and 19 pregnancies were reported.[40]

On the other hand sex cord stromal tumors are treated conservatively only at stage IA and due to the rarity of these tumors and the fact that the peak incidence is in perimenopausal period there are very limited data about fertility and pregnancy outcomes. In a review published by Iavazzo et al about granulosa cell tumors fertility sparing operation was performed in 171 out of 350 patients. 15 patients achieved pregnancy after the operation.[41] In the case of Sertoli-Leydig tumors and sex cord tumors with annular tubules there are not solid data about the pregnancy outcomes after conservative management but there are case reports which mention pregnancies achieved after fertility sparing operations.[42, 43]

Table 2. Summary of pregnancies achieved after fertility sparing operation according to the tumor type

\begin{tabular}{|c|c|c|}
\hline Type of tumor & $\begin{array}{l}\text { Fertility preservation } \\
\text { and pregnancies } \\
\text { achieved }\end{array}$ & $\begin{array}{l}\text { Ratio of pregnancies } \\
\text { achieved at patients with } \\
\text { fertility sparing surgery }\end{array}$ \\
\hline \multicolumn{3}{|l|}{ Germ Cell Tumors } \\
\hline Dysgerminoma & Yes & Zanetta et al. $32 / 138(23.1 \%)$ \\
\hline Yolk-sac tumor & Yes & Tangir et al. 29/64 (45.3\%) \\
\hline Immature teratoma & Yes & Low et al. 19/74 (25.6\%) \\
\hline \multicolumn{3}{|c|}{ Sex Cord Stromal Tumors } \\
\hline Granulosa cell tumor & Yes & Iavazzo et al 15/171 (8.7\%) \\
\hline Sertoli-Leydig Tumors & Insufficient data & \\
\hline $\begin{array}{l}\text { Sex cord tumor with } \\
\text { annular tubules }\end{array}$ & Insufficient data & \\
\hline
\end{tabular}

\section{Conclusion}

In this review we tried to summarize the existing data about non-epithelial ovarian tumors and fertility sparing treatment. Due to the rarity of non-epithelial ovarian cancers and the fact that fertility preservation operation is a fairly new strategy in Gynecologic Oncology there are many aspects that are not completely clear and a universal consensus has not been achieved. In a nutshell, we should mention that fertility sparing operations should be the optimum approach in patients with germ cell tumors given the fact that present mostly in young women and are highly sensitive to platinum-based chemotherapy. On the other hand, patients with sex cord stroll tumors should undergo fertility preservation procedures only in early stage (IA). Last but not least, it is important to highlight the encouraging results concerning fertility preservation and pregnancies achieved after conservative surgical approach of these patients.

\section{Competing Interests}

The authors have declared that no competing interest exists.

\section{References}

1. Monk BJ, Chan JK. American Society of Clinical Oncology 2010 Annual Meeting update: summary of selected gynecologic cancer abstracts. Gynecologic oncology. 2010; 118: 216-9.

2. Smith HO, Berwick M, Verschraegen CF, Wiggins C, Lansing L, Muller CY, et al. Incidence and survival rates for female malignant germ cell tumors.

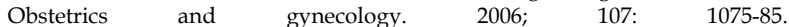
doi:10.1097/01.AOG.0000216004.22588.ce.

3. Mitchell PL, Al-Nasiri N, A'Hern R, Fisher C, Horwich A, Pinkerton CR, et al. Treatment of nondysgerminomatous ovarian germ cell tumors: an analysis of 69 cases. Cancer. 1999; 85: 2232-44.

4. Talerman A. Germ cell tumors of the ovary. Current opinion in obstetrics \& gynecology. 1997; 9: 44-7.

5. dos Santos Silva I, Swerdlow AJ. Ovarian germ cell malignancies in England: epidemiological parallels with testicular cancer. British journal of cancer. 1991; 63: 814-8.

6. Quirk JT, Natarajan N. Ovarian cancer incidence in the United States, 1992-1999. Gynecologic oncology. 2005; 97: 519-23. doi:10.1016/j.ygyno.2005.02.007.

7. Prat J, Oncology FCoG. FIGO's staging classification for cancer of the ovary, fallopian tube, and peritoneum: abridged republication. Journal of gynecologic oncology. 2015; 26: 87-9. doi:10.3802/jgo.2015.26.2.87.

8. Gremeau AS, Bourdel N, Jardon K, Rabischong B, Mage G, Pouly JL, et al. Surgical management of non-epithelial ovarian malignancies: advantages and limitations of laparoscopy. European journal of obstetrics, gynecology, and reproductive biology. 2014; 172: 106-10. doi:10.1016/j.ejogrb.2013.10.023.

9. Colombo N, Peiretti M, Garbi A, Carinelli S, Marini C, Sessa C, et al. Non-epithelial ovarian cancer: ESMO Clinical Practice Guidelines for diagnosis, treatment and follow-up. Annals of oncology : official journal of the European Society for Medical Oncology. 2012; 23 Suppl 7: vii20-6. doi:10.1093/annonc/mds223.

10. Mahdi H, Swensen RE, Hanna R, Kumar S, Ali-Fehmi R, Semaan A, et al. Prognostic impact of lymphadenectomy in clinically early stage malignant germ cell tumour of the ovary. British journal of cancer. 2011; 105: 493-7. doi:10.1038/bjc.2011.267.

11. Morice P, Denschlag D, Rodolakis A, Reed N, Schneider A, Kesic V, et al. Recommendations of the Fertility Task Force of the European Society of Gynecologic Oncology about the conservative management of ovarian malignant tumors. International journal of gynecological cancer : official journal of the International Gynecological Cancer Society. 2011; 21: 951-63. doi:10.1097/IGC.0b013e31821bec6b.

12. Liu Q, Ding X, Yang J, Cao D, Shen K, Lang J, et al. The significance of comprehensive staging surgery in malignant ovarian germ cell tumors. Gynecologic oncology. 2013; 131: 551-4. doi:10.1016/j.ygyno.2013.08.016.

13. Weinberg LE, Lurain JR, Singh DK, Schink JC. Survival and reproductive outcomes in women treated for malignant ovarian germ cell tumors. Gynecologic oncology. 2011; 121: 285-9. doi:10.1016/j.ygyno.2011.01.003.

14. Williams SD, Blessing JA, Hatch KD, Homesley HD. Chemotherapy of advanced dysgerminoma: trials of the Gynecologic Oncology Group. Journal of clinical oncology : official journal of the American Society of Clinical Oncology. 1991; 9: 1950-5. doi:10.1200/JCO.1991.9.11.1950.

15. Kurman RJ, Norris HJ. Endodermal sinus tumor of the ovary: a clinical and pathologic analysis of 71 cases. Cancer. 1976; 38: 2404-19.

16. Willemse PH, Aalders JG, Bouma J, Mulder NH, Verschueren RC, de Vries EG, et al. Long-term survival after vinblastine, bleomycin, and cisplatin treatment in patients with germ cell tumors of the ovary: an update. Gynecologic oncology. 1987; 28: 268-77.

17. Cicin I, Saip P, Guney N, Eralp Y, Ayan I, Kebudi R, et al. Yolk sac tumours of the ovary: evaluation of clinicopathological features and prognostic factors. European journal of obstetrics, gynecology, and reproductive biology. 2009; 146: 210-4. doi:10.1016/j.ejogrb.2009.02.052.

18. Satoh T, Aoki Y, Kasamatsu T, Ochiai K, Takano M, Watanabe Y, et al. Administration of standard-dose BEP regimen (bleomycin+etoposide+cisplatin) is essential for treatment of ovarian yolk sac tumour. European journal of cancer. 2015; 51: 340-51. doi:10.1016/j.ejca.2014.12.004 
19. de La Motte Rouge T, Pautier P, Duvillard P, Rey A, Morice P, Haie-Meder C, et al. Survival and reproductive function of 52 women treated with surgery and bleomycin, etoposide, cisplatin (BEP) chemotherapy for ovarian yolk sac tumor. Annals of oncology : official journal of the European Society for Medical Oncology. 2008; 19: 1435-41. doi:10.1093/annonc/mdn162.

20. Woodruff JD, Protos P, Peterson WF. Ovarian teratomas. Relationship of histologic and ontogenic factors to prognosis. American journal of obstetrics and gynecology. 1968; 102: 702-15.

21. Mangili G, Scarfone G, Gadducci A, Sigismondi C, Ferrandina G, Scibilia G, et al. Is adjuvant chemotherapy indicated in stage I pure immature ovarian teratoma (IT)? A multicentre Italian trial in ovarian cancer (MITO-9). Gynecologic oncology. 2010; 119: 48-52. doi:10.1016/j.ygyno.2010.05.035.

22. Alwazzan AB, Popowich S, Dean E, Robinson C, Lotocki R, Altman AD. Pure Immature Teratoma of the Ovary in Adults: Thirty-Year Experience of a Single Tertiary Care Center. International journal of gynecological cancer : official journal of the International Gynecological Cancer Society. 2015; 25: 1616-22. doi:10.1097/IGC.0000000000000541.

23. Zhang M, Cheung MK, Shin JY, Kapp DS, Husain A, Teng NN, et al. Prognostic factors responsible for survival in sex cord stromal tumors of the ovary--an analysis of 376 women. Gynecologic oncology. 2007; 104: 396-400. doi:10.1016/j.ygyno.2006.08.032.

24. Lee IH, Choi CH, Hong DG, Song JY, Kim YJ, Kim KT, et al. Clinicopathologic characteristics of granulosa cell tumors of the ovary: a multicenter retrospective study. Journal of gynecologic oncology. 2011; 22: 188-95. doi:10.3802/jgo.2011.22.3.188

25. Brown J, Sood AK, Deavers MT, Milojevic L, Gershenson DM. Patterns of metastasis in sex cord-stromal tumors of the ovary: can routine staging lymphadenectomy be omitted? Gynecologic oncology. 2009; 113: 86-90. doi:10.1016/j.ygyno.2008.12.007.

26. Ranganath R, Sridevi V, Shirley SS, Shantha V. Clinical and pathologic prognostic factors in adult granulosa cell tumors of the ovary. International journal of gynecological cancer : official journal of the International Gynecological Cancer Society. 2008; 18: 929-33. doi:10.1111/j.1525-1438.2007.01154.x.

27. Colombo N, Parma G, Zanagnolo V, Insinga A. Management of ovarian stromal cell tumors. Journal of clinical oncology : official journal of the American Society of Clinical Oncology. 2007; 25: 2944-51. doi:10.1200/JCO.2007.11.1005.

28. Schumer ST, Cannistra SA. Granulosa cell tumor of the ovary. Journal of clinical oncology : official journal of the American Society of Clinical Oncology. 2003; 21: 1180-9. doi:10.1200/JCO.2003.10.019.

29. Ghosh A, Ghartimagar D, Thapa S, Sathian B, Narasimhan R, Talwar OP. Ovarian Tumors: Pattern of Histomorphological Types- A 10 Years Study in a Tertiary Referral Center and Review of Literature. Kathmandu University medical journal. 2016; 14: 153-8.

30. Young RH, Scully RE. Ovarian Sertoli-Leydig cell tumors. A clinicopathological analysis of 207 cases. The American journal of surgical pathology. 1985; 9: 543-69.

31. Young RH, Welch WR, Dickersin GR, Scully RE. Ovarian sex cord tumor with annular tubules: review of 74 cases including 27 with Peutz-Jeghers syndrome and four with adenoma malignum of the cervix. Cancer. 1982; 50: 1384-402.

32. Kalifat R, de Brux J. Ovarian sex cord tumor with annular tubules: an ultrastructural study. International journal of gynecological pathology : official journal of the International Society of Gynecological Pathologists. 1987; 6: $380-8$

33. Singh M, Mandal S, Majumdar K. Sex cord tumor with annular tubules: an incidental finding in an endometriotic cyst--the first known cooccurrence. BioMed research international. 2014; 2014: 970243 doi:10.1155/2014/970243.

34. Boussios S, Moschetta M, Zarkavelis G, Papadaki A, Kefas A, Tatsi K. Ovarian sex-cord stromal tumours and small cell tumours: Pathological, genetic and management aspects. Critical reviews in oncology/hematology. 2017; 120: 43-51. doi:10.1016/j.critrevonc.2017.10.007.

35. Qian Q, You Y, Yang J, Cao D, Zhu Z, Wu M, et al. Management and prognosis of patients with ovarian sex cord tumor with annular tubules: a retrospective study. BMC cancer. 2015; 15: 270. doi:10.1186/s12885-015-1277-y.

36. Kumar S, Shah JP, Bryant CS, Imudia AN, Cote ML, Ali-Fehmi R, et al. The prevalence and prognostic impact of lymph node metastasis in malignant germ cell tumors of the ovary. Gynecologic oncology. 2008; 110: 125-32. doi:10.1016/j.ygyno.2008.04.022.

37. Nasioudis D, Kanninen TT, Holcomb K, Sisti G, Witkin SS. Prevalence of lymph node metastasis and prognostic significance of lymphadenectomy in apparent early-stage malignant ovarian sex cord-stromal tumors. Gynecologic oncology. 2017; 145: 243-7. doi:10.1016/j.ygyno.2017.03.005

38. Zanetta G, Bonazzi C, Cantu M, Binidagger S, Locatelli A, Bratina G, et al. Survival and reproductive function after treatment of malignant germ cell ovarian tumors. Journal of clinical oncology : official journal of the American Society of Clinical Oncology. 2001; 19: 1015-20. doi:10.1200/JCO.2001.19.4.1015

39. Tangir J, Zelterman D, Ma W, Schwartz PE. Reproductive function after conservative surgery and chemotherapy for malignant germ cell tumors of the ovary. Obstetrics and gynecology. 2003; 101: 251-7.

40. Low JJ, Perrin LC, Crandon AJ, Hacker NF. Conservative surgery to preserve ovarian function in patients with malignant ovarian germ cell tumors. A review of 74 cases. Cancer. 2000; 89: 391-8
41. Iavazzo C, Gkegkes ID, Vrachnis N. Fertility sparing management and pregnancy in patients with granulosa cell tumour of the ovaries. Journal of obstetrics and gynaecology : the journal of the Institute of Obstetrics and Gynaecology. 2015; 35: 331-5. doi:10.3109/01443615.2014.968107.

42. Stavrakis T, Kalogiannidis I, Petousis S, Tsompanidou C, Delkos D, Prapas N, et al. Fertility-sparing management and obstetric outcomes in a 20-year-old patient with a Sertoli-Leydig cell tumor of the ovary: A case report and review of the literature. Oncology letters. 2016; 12: 1079-82. doi:10.3892/ol.2016.4695.

43. Chatziioannidou K, Botsikas D, Tille JC, Dubuisson J. Preservation of fertility in non-Peutz-Jegher syndrome-associated ovarian sex cord tumour with annular tubules. BMJ case reports. 2015; 2015. doi:10.1136/bcr-2014-207841. 